\title{
The Selective Bradycardic Effects of Zatebradine (UL-FS 49) Do Not Adversely Affect Left Ventricular Function in Conscious Pigs with Chronic Coronary Artery Occlusion
}

\author{
Leon J. van Woerkens, Willem J. van der \\ Giessen, and Pieter D. Verdouw \\ Laboratory for Experimental Cardiology, Thoraxcenter, Erasmus \\ University Rotterdam, The Netherlands
}

\begin{abstract}
Summary. This study was designed to test whether the selective bradycardic effects of zatebradine (UL-FS 49) were altered in the setting of chronic mild left ventricular dysfunction secondary to a myocardial infarction. We therefore administered four doses of UL-FS 49 at 15-min intervals (cumulative doses of $10,30,100$, and $300 \mu \mathrm{g} / \mathrm{kg}$ ) to eight normal conscious pigs and to seven pigs in which the left circumflex coronary artery was occluded 3 weeks previously. Left ventricular dysfunction in this second group of animals was manifested by an increase in left ventricular end-diastolic pressure (LVEDP $11 \pm 2 \mathrm{mmHg}$ vs. $7 \pm 1 \mathrm{mmHg}$, respectively; $p<0.05)$ and a decrease in $\mathrm{LVdP} / \mathrm{dt}_{\max }(3020 \pm 210$ mmHg vs. $3720 \pm 210 \mathrm{mmHg}$, respectively; $p<0.05$ ). The results showed that UL-FS 49 was equally effective in reducing heart rate in both groups of animals [from $126 \pm 4$ to 95 \pm 2 beats $/ \mathrm{min}$ and from $140 \pm 5$ to $98 \pm 6$ beats $/ \mathrm{min}$ for the normal animals and for the animals with a chronic myocardial infarction (MI), respectively]. The duration of left ventricular systole was not affected, but the duration of diastole was prolonged from $290 \pm 10 \mathrm{msec}$ to $420 \pm 20 \mathrm{msec}$ in the normal animals and from $250 \pm 10 \mathrm{msec}$ to $430 \pm 30 \mathrm{msec}$ in the animals with MI (both $p<0.05$ ). Up to $100 \mu \mathrm{g} / \mathrm{kg}$ UL-FS 49 did not affect arterial blood pressure, whereas $\mathrm{LVdP} / \mathrm{dt}_{\max }$ and cardiac output decreased by less than $10 \%$ in either group. With the highest dose there were decreases in cardiac output (20\%) and $L V d P / \mathrm{dt}_{\max }(15 \%)$ and a 5-6 $\mathrm{mmHg}$ increase in left ventricular end-diastolic pressure in both groups. The data suggest that UL-FS 49 in doses up to $100 \mu \mathrm{g} / \mathrm{kg}$ may also, in the setting of chronic mild left ventricular dysfunction, be an attractive agent when heart rate has to be reduced selectively.
\end{abstract}

Cardiovasc Drugs Ther 1992;6:59-65

Key Words. selective bradycardic agents, zatebradine heart rate, diastolic perfusion time, left ventricular dysfunction, hemodynamics, myocardial infarction, conscious pig

$\boldsymbol{A}$ reduction in heart rate will improve myocardial oxygen balance by both reducing oxygen demand and improving oxygen supply, in particular of the subendocardial layers, the most vulnerable area of the myocardium. The above are the most important reasons for the antiischemic effects of selective bradycardic agents in the treatment of acute experimental myocardial ischemia [1-4]. Hoffman [5] and Canty et al. [6] recently pointed out that selective bradycardic agents may also be useful to reverse the adverse effect of tachycardia on the lower limit of subendocardial autoregulation. The last group of investigators observed that increasing the heart rate in dogs from 100 to 200 beats/min increased the minimal coronary perfusion pressure needed to ensure normal subendocardial perfusion by $60 \%$ [6]. The mechanisms responsible for this increase in minimal coronary perfusion pressure are believed to be related to the tachycardia-induced myocardial oxygen consumption, which increases autoregulated coronary flow [7] and the tachycardia-induced reduction in diastolic time per minute, which decreases maximal coronary flow [8]. In normal hearts a tachycardia-induced reduction in coronary flow reserve will not lead to subendocardial ischemia, but if coronary flow reserve is already impaired, for instance, due to hypertrophy, myocardial ischemia may ensue when heart rate increases.

UL-FS 49 (1,3,4,5-tetra hydro-7,8-dimethoxy-3[3[2-(3,4-dimethoxyphenyl)-ethyl]-methylamino] propyl]2H-3-benzazepin-2-on-hydrochloride; Fig. 1) is a socalled specific bradycardic agent, which lowers heart rate by a mechanism other than beta-adrenoceptor or calcium-channel blockade $[9,10]$, although there are structural similarities with verapamil. Similar to alinidine, the mode of action of UL-FS 49 may be by an effect on anionic channels [11] or by the $I_{f}$ channel $[12,13]$. UL-FS 49 has been shown to predominantly reduce heart rate $[9,10]$ and thereby improves the perfusion and function of acutely ischemic myocardium [2-4]. The effects of UL-FS 49 in animals with chronic left ventricular dysfunction have not yet been

Address for correspondence and reprint requests: Pieter D. Verdouw, PhD, Laboratory for Experimental Cardiology, Thoraxcenter, Erasmus University Rotterdam, P.O. Box 1738, 3000 DR Rotterdam, The Netherlands. 


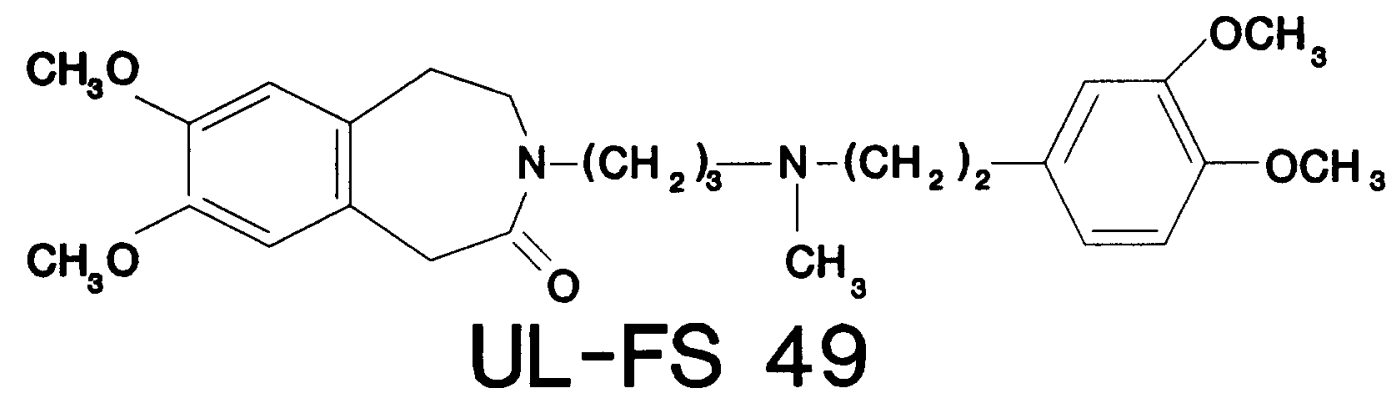

Fig. 1. The chemical structure of zatebradine (UL-FS 49).

studied. We have, however, shown that in conscious pigs chronic left ventricular dysfunction may alter the quantitative, as well as the qualitative, effects of cardiovascular drugs $[14,15]$. Furthermore, when left ventricular function is chronically impaired, a reduction in heart rate by $\beta$-adrenoceptor blockade often leads to a further deterioration of cardiovascular performance due to unwanted negative inotropy [15]. In the present study we therefore evaluated the cardiovascular effects of UL-FS 49 in conscious pigs with a 3-week-old myocardial infarction and compared the results to those obtained in a group of pigs with normal hearts, in order to establish whether the cardiovascular effects of UL-FS 49, in particular on diastolic perfusion time, were affected by the chronic left ventricular dysfunction.

\section{Materials and Methods}

\section{Surgical procedures}

The experimental procedures were approved by the Committee on Animal Experiments of the Erasmus University Rotterdam, and complied to the guidelines for the use and care of experimental animals as put forward by the Council of the American Physiological Society [DHEW Publication No. (NIH) 80-23, 1980].

After an overnight fast, 20 crossbred Landrace $\mathrm{x}$ Yorkshire pigs of either sex $(19-21 \mathrm{~kg}$ at the time of surgery), pretreated with $600 \mathrm{mg}$ of a mixture of procaine penicillin- $G$ and benzathine penicillin-G intramuscularly (Duplocillin, Gist-Brocades NV, Delft, The Netherlands), were sedated with an intramuscular injection of $30 \mathrm{mg} / \mathrm{kg}$ ketamine HCL (Aeskoket, Aesculaap BV, Boxtel, The Netherlands). Subsequently the animals were intubated and mechanically ventilated with a mixture of oxygen and nitrous oxide $(1: 2)$ to which $1-4 \%(\mathrm{v} / \mathrm{v})$ enflurance was added. Under sterile conditions, a jugular vein and a common carotid artery were cannulated for infusion of drugs or solvent, and for the measurement of arterial blood pressure, respectively. The chest was opened via the third left intercostal space, and an electromagnetic flow probe (Skalar, Delft, The Netherlands) was posi- tioned around the ascending aorta for the measurement of aortic blood flow. The heart was exposed via the fifth intercostal space, and a Konigsberg pressure transducer (Konigsberg Instrument Inc., Pasadena, $\mathrm{CA}$ ) was implanted into the left ventricle of the heart through its apex for recording of left ventricular pressure. The left atrium was cannulated for the recording of left atrial pressure, which, together with the arterial blood pressure, was used for calibration of the Konigsberg transducer signals.

In 12 animals the proximal segment of the left circumflex coronary artery (LCXCA) was permanently ligated for the induction of a myocardial infarction. Serious ventricular arrhythmias (sustained ventricular tachycardia or ventricular fibrillation) were treated with immediate DC countershock. After 30 minutes the chest was closed and the wires were tunnelled subcutaneously to the back, and the animals were allowed to recover from surgery.

The animals received daily intravenous doses of 500 mg amoxicilline (Clamoxil, Beecham Farma BV, Amstelveen, The Netherlands) and, during the first week only, kanamycin $500 \mathrm{mg}$ (Kanymex, Gist Brocades NV, Delft, The Netherlands) to prevent infection. Catheters were flushed daily with an isotonic saline solution containing $500 \mathrm{IU} / \mathrm{ml}$ heparin. During the first 3 weeks of the postoperative recovery period, the animals were adapted to the laboratory facilities (8-10 sessions), while hemodynamic parameters were monitored. The experimental protocols were executed when systemic hemodynamics and arterial blood gases remained stable for at least 1 hour, usually 3 weeks after instrumentation. All measurements were done while the animals were quietly resting in a constraining jacket.

\section{Mortality}

All eight animals with the intact coronary circulation could be used for the study. From the 12 pigs in which the left circumflex coronary artery was occluded, four animals died suddenly during the postoperative period, most likely secondary to a ventricular arrhythmia. One animal was excluded from the study because of the failure of the electrical transducers. 


\section{Experimental protocols}

After baseline hemodynamic measurements were obtained, each animal received four bolus infusions of UL-FS 49 of $10,20,70$, and $200 \mu \mathrm{g} / \mathrm{kg}$ (cumulative doses of $10,30,100$, and $300 \mu \mathrm{g} / \mathrm{kg}$ ) or the solvent of UL-FS 49 at 15-minute intervals. At the end of each 15 minute period, all hemodynamic measurements were repeated before the next dose was administered. The duration of systole and diastole were determined from the arterial blood pressure recordings. The nadir of diastolic arterial blood pressure was taken as the onset and the occurrence of the incisura as the end of the left ventricular ejection. The experiments with the drug and the solvent were separated by at least 24 hours. Volumes of the solvent corresponded with those administered during the UL-FS 49 infusions.

\section{Drugs}

UL-FS 49 was supplied by Dr. Karl Thomae GmbH (Biberach an der Riss, Germany). The drug was dissolved in saline $(0.9 \% \mathrm{NaCl} \mathrm{w} / \mathrm{v})$ to a concentration of $10 \mu \mathrm{g} / \mathrm{kg} / \mathrm{ml}$.

\section{Statistical analysis}

All data have been presented as mean \pm SEM. Differences between the baseline values of the two groups of animals were evaluated using the unpaired Student's t-test (two tailed). Statistical significance of druginduced changes was determined by comparison to the solvent-induced changed from the same group. A
Bonferroni correction was used because of multiple measurements. Statistical significance was accepted for a probability less than $5 \%$.

\section{Results}

\section{Blood gases}

Arterial blood gases of the normal animals and the animals with chronic left ventricular dysfunction did not differ and were within the limits of those reported earlier for conscious pigs [15], measured with an ABL-3 (Radiometer, Copenhagen, Denmark): $\mathrm{pH} 7.42$ $\pm 0.02, \mathrm{pO}_{2} 75 \pm 3 \mathrm{mmHg}$, and $\mathrm{pCO}_{2} 40 \pm 2 \mathrm{mmHg}$.

\section{Baseline values of systemic hemodynamic of normal pigs and pigs with the infarctions}

The baseline values of the animals with a chronically occluded left circumflex coronary artery showed some significant differences compared with normal conscious animals (Tables 1 and 2). In the former, heart rate was $10 \%$ higher and $\mathrm{LVdP} / \mathrm{dt}_{\max }$ was $20 \%$ lower than in normal animals. The differences in mean arterial blood pressure and stroke volume were not significantly different. Left ventricular filling pressure, however, was significantly higher in the animals with chronic left circumflex coronary artery occlusion (14 \pm 2 vs. $9 \pm 1 \mathrm{mmHg}, \mathrm{p}<0.05$ ). Table 1 also shows that the systemic hemodynamic parameters remained stable in both groups of animals during the infusion of the solvent.

Table 1. Stability of systemic hemodynamic parameters during solvent infusion of eight normal conscious pigs $(N)$ and in seven conscious pigs with a 3-week-old myocardial infarction (MI)

\begin{tabular}{|c|c|c|c|c|c|c|}
\hline & & \multirow[b]{2}{*}{ Baseline } & \multicolumn{4}{|c|}{ Saline (ml) } \\
\hline & & & 1 & 2 & 7 & 20 \\
\hline \multirow[t]{2}{*}{$\mathrm{HR}$} & $\mathrm{N}$ & $121 \pm 9$ & $123 \pm 11$ & $121 \pm 11$ & $120 \pm 12$ & $122 \pm 11$ \\
\hline & MI & $131 \pm 4$ & $130 \pm 4$ & $130 \pm 3$ & $129 \pm 4$ & $131 \pm 4$ \\
\hline \multirow[t]{2}{*}{$\mathrm{CO}$} & $\mathrm{N}$ & $2.64 \pm 0.05$ & $2.63 \pm 0.05$ & $2.63 \pm 0.05$ & $2.59 \pm 0.07$ & $2.61 \pm 0.04$ \\
\hline & MI & $2.52 \pm 0.10$ & $2.52 \pm 0.11$ & $2.51 \pm 0.10$ & $2.50 \pm 0.10$ & $2.50 \pm 0.10$ \\
\hline \multirow[t]{2}{*}{ SAP } & $\mathrm{N}$ & $129 \pm 4$ & $126 \pm 4$ & $126 \pm 3$ & $127 \pm 3$ & $130 \pm 5$ \\
\hline & MI & $119 \pm 4$ & $119 \pm 4$ & $121 \pm 4$ & $120 \pm 4$ & $119 \pm 5$ \\
\hline \multirow[t]{2}{*}{ MAP } & $\mathrm{N}$ & $99 \pm 4$ & $97 \pm 4$ & $98 \pm 4$ & $99 \pm 4$ & $100 \pm 4$ \\
\hline & MI & $97 \pm 4$ & $97 \pm 4$ & $99 \pm 4$ & $97 \pm 4$ & $98 \pm 5$ \\
\hline \multirow[t]{2}{*}{ DAP } & $\mathrm{N}$ & $73 \pm 5$ & $71 \pm 6$ & $72 \pm 5$ & $73 \pm 4$ & $74 \pm 5$ \\
\hline & MI & $76 \pm 2$ & $77 \pm 2$ & $78 \pm 3$ & $77 \pm 2$ & $78 \pm 3$ \\
\hline \multirow[t]{2}{*}{$\mathrm{LVdP} / \mathrm{dt}_{\max }$} & $\mathrm{N}$ & $3640 \pm 270$ & $3520 \pm 280$ & $3420 \pm 250$ & $3510 \pm 350$ & $3680 \pm 310$ \\
\hline & MI & $2720 \pm 200^{*}$ & $2680 \pm 170$ & $2820 \pm 190$ & $2720 \pm 200$ & $2670 \pm 220$ \\
\hline \multirow[t]{2}{*}{ LVEDP } & $\mathrm{N}$ & $9 \pm 1$ & $9 \pm 1$ & $9 \pm 1$ & $9 \pm 1$ & $9 \pm 1$ \\
\hline & MI & $14 \pm 2^{\mathrm{a}}$ & $14 \pm 2$ & $14 \pm 2$ & $15 \pm 2$ & $14 \pm 2$ \\
\hline \multirow[t]{2}{*}{ SV } & $\mathrm{N}$ & $22.2 \pm 1.9$ & $22.0 \pm 2.4$ & $22.4 \pm 2.3$ & $22.1 \pm 2.1$ & $22.1 \pm 2.1$ \\
\hline & MI & $19.2 \pm 0.8$ & $19.5 \pm 0.8$ & $19.3 \pm 0.9$ & $19.5 \pm 0.9$ & $19.1 \pm 0.9$ \\
\hline
\end{tabular}

$\mathrm{HR}=$ heart rate (beats $/ \mathrm{min}) ; \mathrm{CO}=$ cardiac output $(\mathrm{l} / \mathrm{min}) ; \mathrm{SAP}, \mathrm{MAP}$, and DAP are systolic, mean, and diastolic arterial blood pressure $(\mathrm{mmHg})$, respectively; $\mathrm{LVdP} / \mathrm{dt}_{\max }=$ maximal rate of rise of left ventricular pressure $(\mathrm{mmHg} / \mathrm{s}) ; \mathrm{LVEDP}=$ left ventricular end-diastolic pressure $(\mathrm{mmHg}) ; \mathrm{SV}=$ stroke volume $(\mathrm{ml})$.

${ }^{2} \mathrm{p}<0.05$ versus normal pigs (for baseline measurements only). 
Table 2. Systemic hemodynamic effects of UL-FS 49 in eight normal conscious pigs (N) and in seven conscious pigs with a 3-week-old myocardial infarction (MI)

\begin{tabular}{|c|c|c|c|c|c|c|}
\hline & & \multirow[b]{2}{*}{ Baseline } & \multicolumn{4}{|c|}{ UL-FS $49(\mu \mathrm{g} / \mathrm{kg})$} \\
\hline & & & 10 & 20 & 70 & 200 \\
\hline \multicolumn{2}{|l|}{ Total dose } & 0 & 10 & 30 & 100 & 300 \\
\hline \multirow{2}{*}{$\mathrm{HR}$} & $\mathrm{N}$ & $126 \pm 4$ & $125 \pm 4$ & $120 \pm 4^{b}$ & $114 \pm 4^{b}$ & $95 \pm 2^{b}$ \\
\hline & MI & $140 \pm 4$ & $138 \pm 5$ & $133 \pm 6^{\mathrm{b}}$ & $117 \pm 5^{\mathrm{b}}$ & $98 \pm 6^{b}$ \\
\hline \multirow[t]{2}{*}{$\mathrm{CO}$} & $\mathrm{N}$ & $2.65 \pm 0.11$ & $2.55 \pm 0.12^{b}$ & $2.49 \pm 0.12^{\mathrm{b}}$ & $2.45 \pm 0.18^{b}$ & $2.19 \pm 0.12^{\mathrm{b}}$ \\
\hline & MI & $2.58 \pm 0.11$ & $2.54 \pm 0.10$ & $2.46 \pm 0.10^{\mathrm{b}}$ & $2.36 \pm 0.10^{\mathrm{b}}$ & $2.02 \pm 0.20^{b}$ \\
\hline \multirow[t]{2}{*}{ SAP } & $\mathrm{N}$ & $122 \pm 5$ & $122 \pm 5$ & $121 \pm 4$ & $122 \pm 4$ & $124 \pm 6$ \\
\hline & MI & $114 \pm 5$ & $113 \pm 5$ & $114 \pm 5$ & $117 \pm 5$ & $115 \pm 4$ \\
\hline \multirow[t]{2}{*}{ MAP } & $\mathrm{N}$ & $99 \pm 4$ & $100 \pm 4$ & $98 \pm 3$ & $97 \pm 3$ & $95 \pm 4$ \\
\hline & MI & $93 \pm 4$ & $93 \pm 4$ & $94 \pm 4$ & $94 \pm 4$ & $90 \pm 3$ \\
\hline \multirow[t]{2}{*}{ DAP } & $\mathrm{N}$ & $74 \pm 6$ & $77 \pm 5$ & $73 \pm 5$ & $70 \pm 5$ & $66 \pm 7$ \\
\hline & MI & $73 \pm 4$ & $71 \pm 4$ & $73 \pm 4$ & $72 \pm 3$ & $66 \pm 3$ \\
\hline \multirow[t]{2}{*}{$\mathrm{LVdP} / \mathrm{dt}_{\max }$} & $\mathrm{N}$ & $3720 \pm 210$ & $3680 \pm 230$ & $3510 \pm 230^{\mathrm{b}}$ & $3420 \pm 280^{b}$ & $3140 \pm 280^{b}$ \\
\hline & MI & $3020 \pm 210^{\mathrm{a}}$ & $2740 \pm 250^{\mathrm{b}}$ & $2790 \pm 240^{\mathrm{b}}$ & $2720 \pm 220^{b}$ & $2570 \pm 290^{\mathrm{b}}$ \\
\hline \multirow[t]{2}{*}{ LVEDP } & $\mathrm{N}$ & $7 \pm 1$ & $8 \pm 1$ & $8 \pm 1$ & $9 \pm 1^{b}$ & $12 \pm 1^{b}$ \\
\hline & MI & $11 \pm 2^{\mathrm{a}}$ & $12 \pm 2$ & $11 \pm 2$ & $13 \pm 2$ & $16 \pm 3^{\mathrm{b}}$ \\
\hline \multirow[t]{2}{*}{ SV } & $\mathrm{N}$ & $21.7 \pm 1.2$ & $21.2 \pm 1.6$ & $21.4 \pm 1.5$ & $22.5 \pm 1.8$ & $23.6 \pm 1.3$ \\
\hline & MI & $18.6 \pm 1.4$ & $18.5 \pm 1.2$ & $18.3 \pm 1.2$ & $20.0 \pm 1.0^{b}$ & $20.7 \pm 1.4$ \\
\hline
\end{tabular}

$\mathrm{HR}=$ heart rate (beats $/ \mathrm{min}) ; \mathrm{CO}=$ cardiac output $(1 / \mathrm{min})$; SAP, MAP, and DAP are systolic, mean, and diastolic arterial blood pressure $(\mathrm{mmHg})$, respectively; $\mathrm{LVdP} / \mathrm{dt}_{\max }=$ maximal rate of rise of left ventricular pressure $(\mathrm{mmHg} / \mathrm{s}) ; \mathrm{LVEDP}=$ left ventricular end-diastolic pressure $(\mathrm{mmHg}) ; \mathrm{SV}=$ stroke volume $(\mathrm{ml})$.

${ }^{a} p<0.05$ versus normal pigs (for baseline measurements only); ${ }^{b} p<0.05$ versus baseline.

Data have been presented as mean \pm SEM.

\section{Cardiovascular Effects of UL-FS 49}

Table 2 shows that UL-FS 49 was at least as effective in reducing heart rate in the animals with the infarction as in normal animals. As a matter of fact, after the administration of $100 \mu \mathrm{g} / \mathrm{kg}$ (total dose), the reduction in the animals with the infarction was slightly larger ( $23 \pm 3$ beats $/ \mathrm{min}$ ) than in normal animals $(12 \pm 2$ beats $/ \mathrm{min}, \mathrm{p}<0.05)$. At other doses, the reduction in heart rate was, however, very similar. Cardiac output decreased by less than $10 \%$ in both groups until infusion of a cumulative dose of $300 \mu \mathrm{g} /$ $\mathrm{kg}$, which caused cardiac output to decrease by approximately $20 \%$ in both groups. At any dose, the decrease in heart rate was larger than the decrease in cardiac output, and it therefore follows that stroke volume increased (10-15\% at the highest dose). Mean arterial blood pressure was not affected in either group over the entire dose range, which indicates that peripheral vasoconstriction counterbalanced the effect of cardiac output on mean arterial blood pressure at the highest dose. $\mathrm{LVdP} / \mathrm{dt}_{\max }$ decreased in both groups by less than $10 \%$ until the last dose was administered.

During baseline conditions, the duration of systole was the same for both groups of animals, but the duration of diastole was significantly reduced in animals with the infarction (Figure 2). The bradycardic action of UL-FS 49 had no effect on the duration of systole in either group. The duration of diastole was, however, significantly prolonged in a dose-dependent manner in both groups of animals (up to $130 \pm 20 \mathrm{msec}$ in the normal animals and up to $180 \pm 30 \mathrm{msec}$ in the animals with the infarctions).

\section{Discussion}

In patients with stable angina pectoris and normal left ventricular function, selective bradycardic agents offer only a limited advantage above $\beta$-adrenoceptor antagonists, e.g., where the effects on other organs (lungs, liver, thyroid) have to be avoided. However, in patients with left ventricular dysfunction, the direct effects on the heart may become more important. After a myocardial infarction, the unaffected part of the left ventricle has to compensate for the loss in contractile function of the infarcted segment. This may lead to compensatory hypertrophy, which results in a decreased coronary flow reserve. Both $\beta$-adrenoceptor antagonists and selective bradycardic agents, by increasing the diastolic perfusion period, may improve coronary perfusion. On the other hand, the negative inotropic effects of $\beta$-adrenoceptor antagonists may interfere with systolic function, leading to the need for further adaptive mechanisms, such as ventricular dilatation, which in itself decreases subendocardial perfusion [16].

Occlusion of the left circumflex coronary artery in 


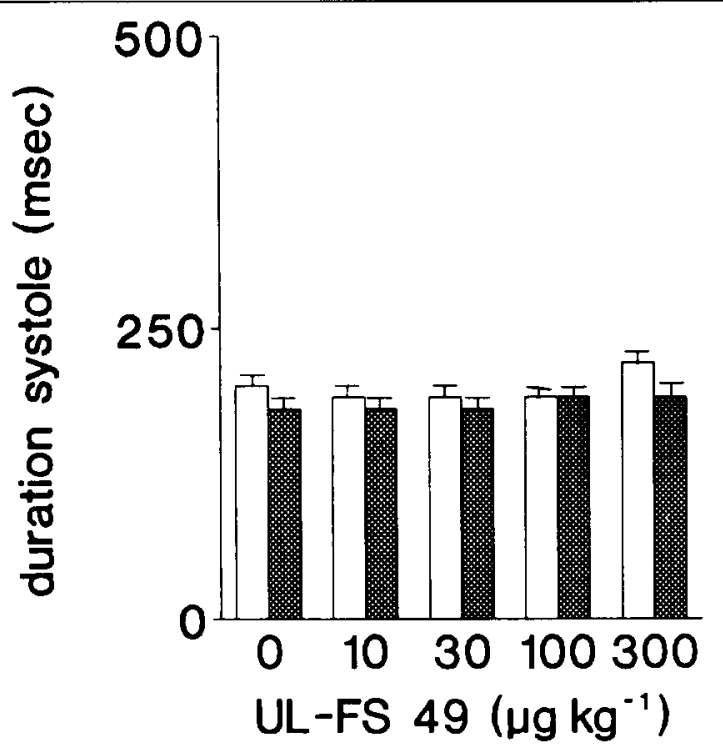

Fig. 2. Effect of UL-FS 49 on the duration of left ventricular systole and on the duration of diastole in eight normal conscious pigs ( $\square$ ) and in seven pigs with a s-week occlusion of the left circumflex coronary artery (ם). The figure illustrates that UL-FS 49 had no effect on the duration of systole but

pigs leads to an infarct size of at least $15 \%$ of the left ventricle [14] and to hypertrophy of the left ventricular anterior wall and septum. Therefore, it may serve as an appropriate model to compare the effects of $\beta$ adrenoceptor antagonists and selective bradycardic agents on global left ventricular function.

The most important finding of the present study is that UL-FS 49 reduced heart rate in conscious pigs with chronic mild left ventricular dysfunction to the same extent as in normal pigs, without adversely affecting cardiac performance. This is important as we have earlier shown that the effects of several drugs were modified when tested in the same model. We have, for example, shown that the positive inotropic actions of the phosphodiesterase inhibitor pimobendan were attenuated and that the depressant effects of propranolol become more apparent in animals with chronic left ventricular dysfunction when compared to the effects in normal animals $[14,15]$. On the other hand, the calcium-channel blockers nisoldipine and elgodipine, which had no effect on left ventricular enddiastolic pressure in normal conscious animals, caused a lowering of the elevated left ventricular pressures in the animals with chronic left ventricular dysfunction $[14,15]$.

UL-FS 49 had no effect on the duration of left ventricular systole, in either group of animals. The prolongation of the RR interval was therefore caused by a prolongation of the duration of diastole. The finding that UL-FS 49, amongst others, had no effect on the duration of systole implies that the drug does not re-

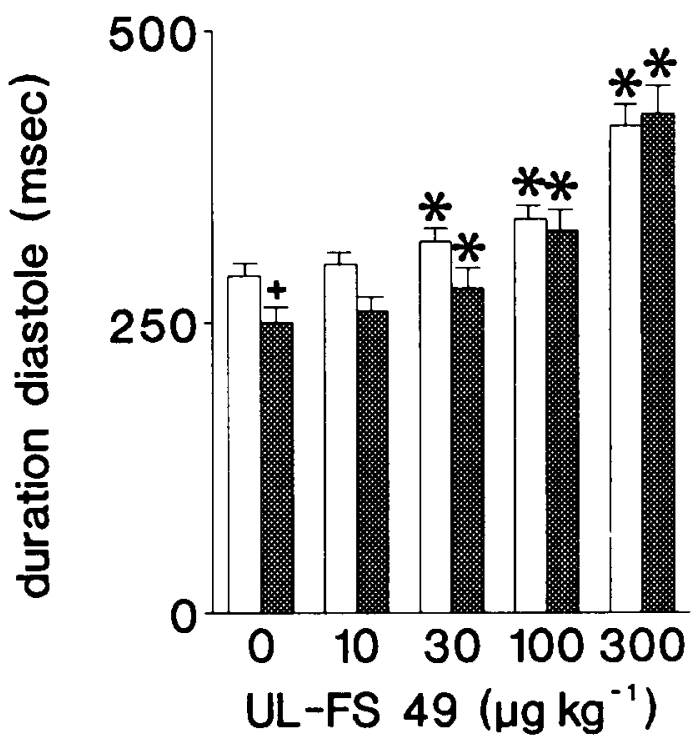

prolonged the duration of diastole to the same extent in both groups of animals. ${ }^{+} p<0.05$ versus normal conscious pigs [only for predrug data (0)]. ${ }^{*} p<0.05$ versus predrug data. The bars indicate the SEM.

duce the myocardial oxygen demand per heart beat, although it will lower the myocardial oxygen demand per minute by reducing the number of systoles per minute. The prolongation of the duration of diastole per heart beat $(47 \%)$ or per minute $(11 \%)$ is therefore probably the most important mechanism for the antiischemic actions of UL-FS 49 [2-4].

The negative chronotropic properties of UL-FS 49 have also been studied in conscious dogs [2-4]. It is noteworthy that in this last species three times higher doses than used in pigs were needed to accomplish similar reductions in heart rate. Furthermore, in these studies in dogs the reductions in heart rate were accompanied by increases (significant or nonsignificant) in $\mathrm{LVdP} / \mathrm{dt}_{\max }[2-4]$, whereas in pigs we found a small but significant decrease in $\mathrm{LVdP} / \mathrm{dt}_{\max }$. The reason for this discrepancy between the two species cannot be easily assessed. Nevertheless, in both anesthetized and conscious pigs the relation between the reduction in heart rate and in $\mathrm{LVdP} / \mathrm{dt}_{\max }$ is more favorable for UL-FS 49 than for its congener falipamil [17] or alinidine $[18,19]$, two other so-called specific bradycardic agents. We also noticed that falipamil and alinidine both decreased $\mathrm{LVdP} / \mathrm{dt}_{\max }$ dose dependently when heart rate was fixed by atrial pacing and that the magnitude of these changes were very similar during pacing and normal sinus rhythm $[17,19]$. This last observation is most likely explained by the observation that, at least in anesthetized pigs, $\mathrm{LVdP} / \mathrm{dt}_{\max }$ is not very sensitive to changes in heart rate in the range of $100-150$ beats/min [20]. In three preliminary 
Table 3. Systemic hemodynamic effects of UL-FS 49 in three normal anesthetized pigs during atrial pacing at 110 beats/min

\begin{tabular}{|c|c|c|c|c|c|c|c|}
\hline & \multirow{2}{*}{$\begin{array}{l}\text { Baseline } \\
\text { prepacing }\end{array}$} & & & & & & \multirow[b]{2}{*}{ Pacing off } \\
\hline & & \multicolumn{5}{|c|}{ UL-FS $49(\mu \mathrm{g} / \mathrm{kg})$} & \\
\hline Total dose & 0 & 0 & 10 & 30 & 100 & 300 & \\
\hline $\mathrm{HR}$ & $101 \pm 2$ & $110 \pm 1$ & $110 \pm 1$ & $110 \pm 1$ & $110 \pm 1$ & $110 \pm 1$ & $74 \pm 3^{\mathrm{a}}$ \\
\hline $\mathrm{CO}$ & $2.0 \pm 0.2$ & $2.1 \pm 0.2$ & $2.1 \pm 0.2$ & $2.0 \pm 0.2$ & $2.0 \pm 0.3$ & $2.1 \pm 0.3$ & $1.8 \pm 0.2$ \\
\hline MAP & $97 \pm 2$ & $99 \pm 2$ & $102 \pm 5$ & $100 \pm 5$ & $100 \pm 7$ & $104 \pm 9$ & $89 \pm 11$ \\
\hline $\mathrm{LVdP} / \mathrm{dt}_{\max }$ & $2420 \pm 280$ & $2220 \pm 330$ & $2250 \pm 370$ & $2200 \pm 340$ & $2160 \pm 360$ & $2210 \pm 420$ & $2300 \pm 370$ \\
\hline SV & $20 \pm 2$ & $19 \pm 2$ & $19 \pm 2$ & $18 \pm 2$ & $18 \pm 2$ & $19 \pm 2$ & $24 \pm 2^{\mathrm{a}}$ \\
\hline
\end{tabular}

$\mathrm{HR}=$ heart rate $($ beats $/ \mathrm{min}) ; \mathrm{CO}=$ cardiac output $(1 / \mathrm{min}) ; \mathrm{MAP}=$ mean arterial blood pressure $(\mathrm{mmHg}) ; \mathrm{LVdP} / \mathrm{dt}_{\max }=\mathrm{maximal} \mathrm{rate}$ of rise of left ventricular pressure $(\mathrm{mmHg} / \mathrm{s}) ; \mathrm{SV}=$ stroke volume $(\mathrm{ml})$.

Data have been presented as mean \pm SEM.

${ }^{a} p<0.05$ versus baseline prepacing.

experiments in anesthetized pigs, we have observed that UL-FS 49 did not significantly decrease $\mathrm{LVdP} /$ $\mathrm{dt}_{\max }$, when heart rate was kept constant by atrial pacing at $110 \mathrm{bpm}$. (Table 3). It thus appears that UL-FS 49 exerts considerably less negative inotropic effects than, for instance, alinidine or falipamil, when heart-rate associated changes in myocardial contractility are excluded.

As was discussed above, $\beta$-adrenoceptor antagonists may also ameliorate myocardial ischemia by a reduction in heart rate. A disadvantage of this class of drugs is that they can substantially decrease myo-

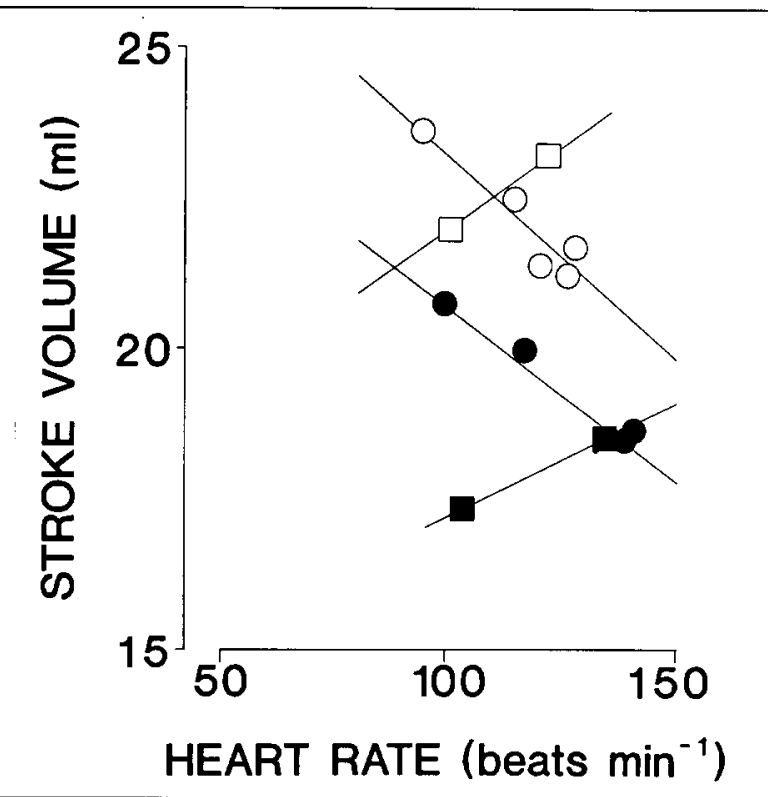

Fig. 3. Relation between changes in heart rate and stroke volume in normal conscions pigs and in conscious pigs with chronic left ventricular dysfunction during the administration of $U L-F S 49(\bigcirc$ and $\bullet$, respectively) and propranolol $(\square$ and D, respectively). Notice that propranolol and UL-FS 49 had opposite effects on stroke volume. The data on propranolol have been reported before [15]. cardial contractility. We have earlier shown that in animals with a 4-week-old myocardial infarction, propranolol at a dose $(0.5 \mathrm{mg} / \mathrm{kg})$ that lowered heart rate by $23 \%$ reduced $\mathrm{LVdP} / \mathrm{dt}_{\max }$ by $32 \%$ [15]. With UL-FS 49 we found that a $30 \%$ lowering of heart rate reduced $\mathrm{LVdP} / \mathrm{dt}_{\max }$ by only $12 \%$ (Table 2 ). Taking into account that $\mathrm{LVdP} / \mathrm{dt}_{\max }$ not only depends on myocardial contractility but also on heart rate and afterload, we like to conclude that the negative inotropic effects of UL-FS 49 are negligible at doses up to $300 \mu \mathrm{g} / \mathrm{kg}$, which is most likely the major reason that UL-FS 49 and propranolol have opposite effects on stroke volume (Figure 3). As discussed by Indolfi et al. [4], reduction of heart rate by UL-FS 49 has also the advantage over $\beta$-adrenoceptor blockade because UL-FS 49 does not cause unmasking of $\alpha$-adrenergic constriction in the large coronary vessels $[21,22]$.

We conclude that, in light of the absence of a depression of cardiovascular performance, the data presented in this study suggest that UL-FS 49 could be an attractive agent to selectively reduce heart rate during chronic mild left ventricular dysfunction. Further studies evaluating the effects of chronic treatment of UL-FS 49, therefore, appear to be the logical next approach.

\section{Acknowledgments}

The authors gratefully acknowledge the secretarial assistance of Ms. Marjo van Ee. Ms. Sylvia Schotman is thanked for her assistance during the experiment. This study was supported by a grant from Dr. Karl Thomae GmbH, Biberach an der Riss, Germany.

\section{References}

1. Schamhardt HC, Verdouw PD, Saxena PR. Improvement of perfusion and function of ischaemic porcine myocardium after reduction of heart rate by alinidine. $J$ Cardiovasc Pharmacol 1981;3:728-738. 
2. Guth BB, Heusch G, Seitelberger R, Ross J. Elimination of exercise-induced regional myocardial dysfunction by a bradycardic agent in dogs with chronic coronary stenosis. Circulation 1987;75:661-669.

3. Krumpl G, Winkler M, Schneider W, Raberger G. Comparison of the haemodynamic effects of the selective bradycardic agent UL-FS 49, with those of propranolol during treadmill exercise in dogs. Br J Pharmacol 1988;94:55-64.

4. Indolfi C, Guth BD, Miura T, et al. Mechanisms of improved ischemic regional dysfunction by bradycardia. Circulation 1989;80:983-993.

5. Hoffman JIE. Autoregulation and heart rate. Circulation 1990;82:1880-1881.

6. Canty JM, Giglia J, Kandath GJ. Effect of tachycardia on regional function and transmural myocardial perfusion during graded coronary pressure reduction in conscious dogs. Circulation 1990;82:1815-1825.

7. Drake-Holland AJ, Laird JD, Noble MIM, et al. Oxygen and coronary vascular resistance during autoregulation and metabolic vasodilation in the dog. $J$ Physiol (Lond) 1984;348:285-299.

8. Raff WK, Kosche F, Lochner W. Extravascular coronary resistance and its relation to microcirculation. Am J Cardiol 1972;29:598-603.

9. Kobinger $W$, Lillie $C$. Cardiovascular characterization of UL-FS 49, 1,3,5-tetrahydro-7,8-dimethoxy-3-[[2-(3,4-dimethoxyphenyl)ethyl]methylimino]propyl]-2H-3-benzazepin-2on-hydrochloride, a new "specific bradycardic agent." Eur $J$ Pharmacol 1984;104:9-18.

10. Lillie $\mathrm{C}$, Kobinger $W$. Investigations into the bradycardic effects of UL-FS 49 (1,3,5-tetrahydro-7,8-dime-thoxy-3[[2-(3,4-dimethoxyphenyl)ethyl]methylimino]propyl]-2H-3benzazepin-2-on-hydrochloride) in isolated guinea pig atria. $J$ Cardiovasc Pharmacol 1986;8:791-797.

11. Millar JS, Vaughan Williams EM. Pacemaker selectivity: Influence on rabbit atria of ionic environment and alinidine, a possible anion antagonist. Cardiovasc Res 1981;15: $335-350$.

12. Bouman LN, Jongsma HJ, Opthof T, van Ginneken ACG. Does $\mathrm{I}_{\mathrm{f}}$ contribute to the pace making in the rabbit sinoatrial node? J Physiol 1985;358:51P.
13. Snyders DJ, Bogaert van PP. Mode of action of alinidine, a new bradycardic agent: A voltage clamp study, $J \mathrm{Am}$ Coll Cardiol 1985;5:494.

14. Van der Giessen WJ, Van Woerkens LJ, Duncker DJ, et al. Acute hemodynamic effects of nisoldipine and pimobendan in conscious pigs with chronic heart failure. $J$ Cardiovasc Pharmacol 1989;14:653-658.

15. Van Woerkens LJ, Schotman SN, Van der Giessen WJ, Verdouw PD. Cardiovascular effects of elgodipine in conscious pigs with a normal coronary circulation and in conscious pigs with a healed myocardial infaretion. $J$ Cardiovasc Pharmacol, 1991;17:976-982.

16. Bache RJ. Effects of hypertrophy on the coronary circulation. Prog Cardiovasc Dis 1988;31:403-440.

17. Verdouw PD, Bom HPA, Bijleveld RE. Cardiovascular responses to increasing plasma concentrations of AQ-A $39 \mathrm{Cl}$, a new compound with negative chronotropic effects. Arzneim Forsch/Drug Res 1983;33:702-706.

18. Verdouw PD, Duncker DJ, Heere ThJM, Saxena PR. Changes in systemic haemodynamics, regional myocardial function and perfusion induced by alinidine in pigs with and without narrowed coronary arteries. Eur Heart $J$ 1987;8(Suppl L):43-52.

19. Verdouw PD, Saxena PR, Schamhardt HC, et al. The effects of alinidine, an $\mathrm{N}$-allyl derivative of clonidine on regional myocardial perfusion and performance in the pig with or without atrial pacing. EurJ Pharmacol 1980;64:209-220.

20. Scheffer MG, Verdouw PD. Decreased incidence of ventricular fibrillation after an acute coronary artery ligation in exercised pigs. Basic Res Cardiol 1983;78:298-309.

21. Kobinger W. Specific bradycardic agents, a new approach to therapy in angina pectoris. Prog Pharmacol 1985;5:89-100.

22. Riley DC, Gross GJ, Kampine JP, Warltier DC. Specific bradycardic agents, a new approach to therapy in angina pectoris. Prog Pharmacol 1985;5:89-100.

22. Riley DC, Gross GJ, Kampine JP, Warltier DC. Specific bradycardic agents, a new therapeutic modality for anesthesiology: Hemodynamic effects of UL-FS 49 and propranolol in conscious and isofluorane-anesthetized dogs. Anesthesiology 1987;67:707-716. 